\title{
Dynamical process upscaling for deriving catchment scale state variables and constitutive relations for meso-scale process models
}

\author{
E. Zehe ${ }^{1}$, H. Lee ${ }^{2}$, and M. Sivapalan ${ }^{3}$ \\ ${ }^{1}$ Institute of Geoecology, University of Potsdam, Germany \\ ${ }^{2}$ Centre of Water Research, University of Western Australia, Crawley, Australia \\ ${ }^{3}$ Departments of Geography and of Civil \& Environmental Engineering, University of Illinois at Urbana-Champaign, USA
}

Received: 13 January 2006 - Published in Hydrol. Earth Syst. Sci. Discuss.: 17 July 2006

Revised: 19 September 2006 - Accepted: 4 December 2006 - Published: 20 December 2006

\begin{abstract}
In this study we propose an uspcaling approach to derive time series of (a) REW scale state variables, and (b) effective REW scale soil hydraulic functions to test and parameterise models based on the REW approach. To this end we employed a physically based hydrological model, that represents the typical patterns and structures in the study catchment, and has previously been shown to reproduce observed runoff response and state dynamics well. This landscapeand process-compatible model is used to simulate numerical drainage and wetting experiments. The effective soil water retention curve and soil hydraulic conductivity curve are derived using the spatially averaged saturation and capillary pressure as well as averaged fluxes. When driven with observed boundary conditions during a one year simulation the model is used to estimate how the spatial pattern of soil moisture evolved during this period in the catchment. The time series of the volume integrated soil moisture is deemed as best estimate for the average catchment scale soil moisture. The approach is applied to the extensively monitored Weiherbach catchment in Germany. A sensitivity analysis showed that catchment scale model structures different from the landscape- and process compatible one yielded different times series of average catchment scale soil moisture and where not able to reproduce the observed rainfall runoff response. Hence, subscale typical heterogeneity leaves a clear fingerprint in the time series of average catchment scale saturation. In case of the Weiherbach catchment local scale heterogeneity of ks could be neglected and a simple representation of the typical hillslope scale patterns of soil types and macroporosity was sufficient for obtaining effective REW scale soil hydraulic functions. Both the effective soil hydraulic functions and time series of catchment scale saturation turned out to be useful to parameterise and test the CREW model, which is based on the REW approach and was
\end{abstract}

Correspondence to: E. Zehe

(ezehe@rz.uni-potsdam.de) applied to the Weiherbach catchment in a companion study Lee et al. (2006, this issue).

\section{Introduction}

Solving the problem of "predictions in ungauged basins" (PUB) is clearly one of the biggest contemporary challenges in hydrological science. Predictions in ungauged or poorly gauged catchments for water resources planning, but also predictions of global change impact even in gauged catchments, seem hardly possible with the kind of predictive tools or models that we currently have that rely so much on calibration (Sivapalan et al., 2003). Meso-scale hydrological models of the conceptual variety only mimic hydrological behaviour a posteriori, i.e., after calibration to precipitation and stream flow data that are available for catchment states that we are interested in. These models are not capable of predicting hydrological response for catchment states outside the range for which precipitation and stream flow data are available. Fully physically based, distributed hydrological models such as MIKE SHE (Refsgaard and Storm, 1995) or CATFLOW (Zehe et al., 2001) may, in principle, be used to extrapolate beyond this "range of experience", because they are based on formulations of universal conservations laws, which essentially means that state variables and model parameters must be measurable quantities. Furthermore, such models are able to explicitly resolve spatial patterns of key variables, which allows us, (a) to test/improve our perception of how spatial patterns control hydrological processes of interest, and consequently (b) may be adopted to support the design of field experiments. However, the application of distributed, physically based hydrological models is only reasonable if spatially highly resolved data sets, with detailed information on the patterns of surface and subsurface hydraulic properties, are available, and for this reason is restricted to the hillslope and small catchment scales for which such data

Published by Copernicus GmbH on behalf of the European Geosciences Union. 
sets may be available in only a limited number of catchments worldwide.

Therefore, solving the PUB problem requires that we:

- Develop a new generation of hydrological models for the meso-scale, that are, on the one hand, based on conservation principles, meaningful state variables and parameters that may be derived from field observations using appropriate upscaling. On the other hand, these models have to be less complex than traditional physically based distributed models, so that parameter estimation remains a tractable problem.

- Change our modelling attitude from ad hoc model modifications, when and if models do not fit the data, more towards model development that is oriented towards rigorous testing of hypotheses, to increase the understanding or explanations of why our models fail.

The TOPKAPI model introduced by Liu and Todini (2002) is a partly physically based model that has been successfully applied for flood predictions in the Xixian catchment in China (Liu et al., 2005). However, the derivation of the underlying process descriptions lacks physical and mathematical rigor and the application to the Xixian catchment is based on calibration. The Representative Elementary Watershed (REW) approach (Reggiani et al., 1998, 1999, 2000) offers an appropriate theoretical framework for developing meso-scale hydrological models with the key characteristics that were highlighted above. The "heart" of the REW approach is a set of coupled mass and momentum balance equations for "different zones" represented within the appropriately chosen representative elementary watershed or REW, which are the unsaturated zone (u-zone), saturated zone (szone), concentrated overland flow zone (c-zone), saturated overland flow zone (o-zone), and channel zone. Mass and momentum fluxes between these different zones within the REW, and the corresponding fluxes between different REWs within a larger watershed, are generally unknown. "Closing" this set of model equations in order to make them determinate (that the number of equations equals the number of unknowns), essentially means, to assess reasonable process formulations for these mass exchanges as functions of REW scale state variables and catchment characteristics so that the set of balance equations becomes mathematically tractable. A second problem which is closely related to this "closure problem" is the assessment of model parameters and effective REW scale constitutive relations which connect different state variables, e.g. the relationship between REW-scale capillary pressure and REW-scale saturation in the unsaturated zone, which incorporate within them the effects of spatial patterns of associated variables within the REW at a lower level of scale (Reggiani et al., 2005; Zehe et al., 2005b).

The focus of the present study is on the assessment of such effective REW scale constitutive relations for the implementation into the CREW model that is introduced and success- fully applied to the Weiherbach catchment within a closely related study of Lee et al. (2006, this issue). Our approach is essentially based on the disaggregation-aggregation approach of Sivapalan (1993) and Viney and Sivapalan (2004), and more specifically the "scale-way" idea of Vogel and Roth (2003). The latter authors argue that upscaling in environmental modelling, in general, has to deal alternatively with both "texture" and "structures". Texture is not explicitly resolved in the model and associated processes are described by means of continuum mechanics. Structures, on the other hand, can and have to be explicitly spatially resolved in the model. Structures at the next lower spatial scale or "subscale" determine partly the dynamics in the "texture" and hence the textural properties at the higher spatial scale. Employing these ideas for physically based, distributed hydrological models, the soil matrix is the texture, described by Richards equation and soil hydraulic functions that represent the effects of subscale structures such as the pore size distribution and the topology of the pore space on water fluxes at the REV scale (Vogel et al., 2005). Structures, on the other hand, refer to the spatial patterns of soil heterogeneities, layering and any preferential pathways, when they exist. Moving on from the REV scale to the REW scale it is obvious that structures i.e. spatial patterns of soils and preferential pathways inside a catchment/a control volume will strongly determine average mass exchange fluxes in the "texture" at the REW scale.

The most fundamental assumptions underlying the proposed study are 1) that capillarity is still of crucial importance for groundwater recharge and capillary rise at the REW scale and 2) that this can accounted for by effective relations that link average capillary pressure and average saturation as well as effective hydraulic conductivity and average saturation. The second postulate implies the assumption of a local equilibrium that will be discussed in Sect. 2. Ideally we would derive this effective soil hydraulic relations based on measurements of average flows and average soil moisture dynamics at the catchment/REW scale for the catchment of interest. However, with current measurement techniques such data are far out of reach. Of course one can assume a functional foem of the "soil water characteristics" and calibrate the parameters, as suggested by Zhang and Savenije (2005) within their successful application of REWASH to the Geer River in Belgium. However, for PUB we have to assess these constitutive relations without calibration!

The key objectives of the present study are to explore to which extend we may obtain effective REW scale constitutive relations by upscaling by using REV scale information and observations. To this end we propose a "dynamical" upscaling approach for (a) generating the time series of REW scale state variables that may assist towards model validation, as well as (b) deriving REW scale constitutive relations which embed the net effects of the dominating patterns and heterogeneity that exist at the sub-REW scale. The proposed approach is implemented in the extensively monitored 
Weiherbach catchment in the South-West of Germany. Both objectives have a strong conceptual link, as they are based on the fundamental idea that fingerprints of subscale patterns and structures may be embedded into spatially averaged output of a distributed model. Therefore, in both cases we employ the structure and the averaged output of a detailed distributed, physically based, hydrological model, which has been previously shown to reproduce well the hydrological dynamics in the study catchment at a range of scales (Zehe et al., 2001, 2005a; Zehe and Blöschl, 2004). In an accompanying paper that appears in this special issue, Lee et al. (2006) present a successful application of a numerical model, CREW, which is based on the REW approach, also to the Weiherbach catchment. In their paper the REW approach and the derivation of closure relations is described in detail. These authors used effective REW-scale soil hydraulic relations of the same functional form as proposed in this study. However, the related parameters were manually calibrated from the integrated output of the spatially distributed model. Based on the upscaling approach presented here we hope to succeed in deriving effective REW scale soil hydraulic relations with similar parameters as those calibrated from Lee et al. (2006) but without calibration. Furthermore, the REWscale state variables obtained from the present study shall serve as target measures for validating the CREW model.

This paper is organized as follows. After explaining the dynamical upscaling methodology in Sect. 2 we will introduce the study area and the available database. Necessary details of the model and the model setup are presented in Sect. 3. The derived REW scale state variables and constitutive relations are presented and discussed in Sect. 4. Finally, we will close with a summary and conclusions in Sect. 5.

\section{Concepts of the dynamical upscaling approach}

\subsection{Basic idea}

The idea to assess effective parameters in order to parameterize subscale heterogeneity within meso-scale hydrological models has been addressed by different studies in the past. Binley et al. (1989a) used a full three dimensional model based on Richards equation coupled with a simple linear routing approach for deriving hillslope scale effective hydraulic conductivities for stochastically generated heterogeneous parameter fields. This worked for weakly heterogeneous systems of high average hydraulic conductivities ranging for 0.05 to $0.2 \mathrm{~cm} / \mathrm{min}$ (compare their Table 2). But they did not succeed in obtaining effective hydraulic conductivities that yielded good results for subsurface and surface flow at the same time in case of systems of low average permeability (see their Table 3). For an effective description of tracer transport in heterogeneous aquifers Dagan (1989) and Gelhar (1993) proposed perturbation methods for assessing first and second moments of tracer plumes groundwater. At- tinger (2003) and Lunati et al. (2002) proposed volume averaging and homogenisation techniques for deriving effective process descriptions and parameterisations for an equivalent homogeneous medium at larger spatial scales.

The latter approaches focused on groundwater modelling, often assuming log-normally distributed random transmissivities, which allowed them to successfully employ analytical techniques. This works well for weakly heterogeneous and linear systems. In the unsaturated zone within a catchment, however, subsurface water fluxes are determined by patterns of vegetation, soil layering and preferential pathways, which interact amongst each other in a highly nonlinear way. Analytical averaging techniques are therefore not appropriate because they (a) cannot account for the nonlinear interactions of this multitude of spatial patterns, and (b) the spatial variability of key soil parameters is only partially of a statistical type, a large part of variability is of the structural type. The principal difference between the above listed approaches and the upscaling approach presented here is to use, similar to the study of Binley et al. (1989b), the spatially averaged output of a numerical process model for dynamic upscaling. A detailed numerical model does naturally account for the nonlinear multiple influences of different patterns on the subsurface fluxes. However, in contrast to the study of Binley et al. (1989b), which was based for a hypothetical hillslope, our study is carried out for the very well observed Weiherbach catchment and model structure that has been shown to portray systems response on different spatio-temporal scales.

Zehe et al. (2001) showed that in this catchment, which is situated in a Loess area in Germany, a model structure which only incorporates typical (not actual) spatial patterns of soil types, vegetation and preferential pathways in that Loess landscape, and neglects local scale statistical variability, is sufficient to explain a large part of the observed variability of hydrological processes at the catchment scale. Within a 1.5-year simulation the catchment model predicted catchment scale runoff response with a Nash-Sutcliffe efficiency of 0.82 , explained more than $92 \%$ of the evapo-transpiration rates (ET) observed at a meteorological station and yielded at the same time reasonable predictions of soil moisture time series observed at 61 locations in the catchment with correlation coefficients ranging between 0.65 and 0.75 (Zehe et al., 2001, 2005a). In this study we will employ this "landscapeand process-compatible" model structure for the implementation of the dynamical upscaling approach.

\subsection{Derivation of catchment scale average state measures}

To address the first objective, i.e. the derivation of time series of catchment scale state variables, we will employ the full catchment model (with the landscape- and process- compatible structure) with observed boundary conditions. As the model simulates the full hydrological cycle (please compare Sect. 3.2 for a brief model description) the simulated state variables such as soil moisture evolve in a manner that 
is physically consistent with the other simulated processes (such as surface runoff and ET) and the dominant patterns in this catchment that are explicitly represented in the model. As the model yields good estimates of the observed runoff response, ET and soil moisture during this period we postulate that space-time- fields of soil moisture $\theta_{\text {sim }}(\mathrm{x}, \mathrm{y}, \mathrm{z}, \mathrm{t})$ and the matric potential $\psi_{\operatorname{sim}}(\mathrm{x}, \mathrm{y}, \mathrm{z}, \mathrm{t})$ represent the best approximation to the real, unknown patterns of soil moisture $\theta_{\text {real }}(\mathrm{x}, \mathrm{y}, \mathrm{z}, \mathrm{t})$ and matric potential $\psi_{\text {real }}(\mathrm{x}, \mathrm{y}, \mathrm{z}, \mathrm{t})$ that will evolve in this catchment under the given boundary conditions. By integrating the model output over the total catchment volume and dividing by the catchment volume, we can obtain the time series of catchment-scale average soil moisture $\bar{\theta}(\mathrm{t})$ $\left[\mathrm{L}^{3} \mathrm{~L}^{-3}\right]$ and catchment-scale average matric potential $\Psi(\mathrm{t})$ [L]:

$$
\begin{aligned}
& \bar{\theta}(t)=\frac{1}{V_{\text {Catchment }}} \iiint \int_{\text {Catchment }} \theta_{\operatorname{sim}}(x, y, z, t) \mathrm{d} x \mathrm{~d} y \mathrm{~d} z \\
& \Psi(t)=\frac{1}{V_{\text {Catchment }}} \iiint_{\text {Catchment }} \psi_{\text {sim }}(x, y, z, t) \mathrm{d} x \mathrm{~d} y \mathrm{~d} z
\end{aligned}
$$

where $x, y, z$ denote the Cartesian coordinates and $t$ the time.

As we consider these average state variables, derived from the landscape- and process-compatible model structure, as physically consistent with local observations, we postulate that these series of catchment-scale average soil moisture and matric potential may be used as additional target measures for validation of meso-scale models developed for this area. The following sections present the application of this approach for the Weiherbach catchment.

2.3 Derivation of effective constitutive relations for the unsaturated zone of the CREW model

The second objective of this study is to propose an approach for deriving REW scale effective constitutive relations that link a) REW scale capillary pressure to the REW scale saturation of the unsaturated zone (an effective REW scale water retention curve) as well as b) the effective REW scale unsaturated hydraulic conductivity to the REW scale saturation of the unsaturated zone. The CREW model (Lee et al., 2006) employs these two constitutive relations exclusively in the closure relation that describes the mass exchange flux between the unsaturated and the saturated zone (compare Eq. 2). By assuming no exchanges between neighbouring REWs, the mass balance equation for the unsaturated zone is given as follows (Lee et al., 2006):

$$
\begin{gathered}
\frac{\mathrm{d}}{\mathrm{d} t}\left(\rho \varepsilon y^{u} s^{u} \omega^{u}\right)= \\
\underbrace{e^{u A}}_{\text {evapotranspiration }}+\underbrace{e^{u s}}_{\text {recharge or capillary rise }}+\underbrace{e^{u c}}_{\text {infiltration }}
\end{gathered}
$$

where $y^{u}[\mathrm{~L}]$ is the average thickness of the unsaturated zone, $s^{u}[-]$ is the average saturation ranging from zero to one, $\omega^{u}\left[\mathrm{~L}^{2}\right]$ is the area fraction of the unsaturated zone in the REW/catchment, $\varepsilon^{u}\left[\mathrm{~L}^{3} \mathrm{~L}^{-3}\right]$ is the porosity, and $\rho\left[\mathrm{ML}^{-3}\right]$ is the mass density of water. The flux densities $e^{u A}, e^{u s}$, $e^{u c}$ denote the mass exchange rates at the interface to the atmosphere, saturated zone and concentrated overland flow zone, respectively.

As exclusively the exchange term $e^{u s}$, which denotes groundwater recharge or capillary rise, accounts for REW scale constitutive relations, we omit the expression for the other exchange terms in Eq. (2) (please refer to Lee et al., 2006). The expression for $e^{u s}$ proposed by Lee et al. (2006) is based on the following assumptions. Capillary forces and gravity are still the major drivers for groundwater recharge and capillary rise at the REW scale. The mass flux $e^{u s}$ is still driven by average gradients of matric potential and gravity, that catchment-scale average water saturation $s^{u}$ in the unsaturated zone is related to catchment-scale average capillary pressure $\psi$ by an average water retention function, and that the average flow resistance may be described by an effective REW-scale unsaturated hydraulic conductivity $\bar{k}$, which is also a function of average saturation $s^{u}$. Hence, $e^{u s}$ is given by Lee et al. (2006):

$$
\begin{aligned}
e^{u s} & =\alpha^{u s} s^{u} w^{u} v_{z}^{u} \\
v_{z}^{u} & =\frac{\bar{k}}{s^{u} y^{u}}\left[\frac{1}{2}|\Psi|-y^{u}\right] \\
\Psi & =f\left(s^{u}\right)
\end{aligned}
$$

where $\alpha^{u s}$ is a dimensionless scaling parameter.

The basic idea of the present study is to select a Brooks and Corey type function for $\bar{k}\left(\mathrm{~s}^{u}\right)$ and $\Psi=f\left(s^{u}\right)$ as suggested in Lee et al. (2006) or Zhang and Savenije (2005). Contrary to these authors, who calibrated the corresponding parameters manually, we will estimate the parameters from simulated drainage and wetting experiments carried out with the landscape- and process-compatible model for artificial boundary conditions (either the full catchment model or if possible just by employing the hillslope module for typical hillslope structures) without any calibration. In this sense, the detailed numerical model represents a catchment/hillslope scale measurement instrument. To this end, we start either at an initially saturated or and initially dry catchment/hillslope and impose an increasing suction head/a constant suction head equal to zero at the lower boundary of the catchment. The boundary conditions at the remaining boundaries are of the zero flux type. The simulated outflow/inflow $q\left(x, y, z_{B}, t\right)$ at the lower boundary, i.e. at a defined depth in the soil $z_{B}$, is averaged over the whole catchment/hillslope area for each time step.

$e^{s u}(t)=\frac{1}{A_{\text {Catchment }}} \iint_{\text {Area }} q\left(x, y, z_{B}, t\right) \mathrm{d} x \mathrm{~d} y$

Additionally, the simulated saturation and the matric potential are averaged over the simulation domain, as defined in Eq. (1). This way we obtain series of values of average outflows/inflows $e^{s u}$ as a function of average saturation $s^{u}$. If Eq. (3) is now solved for $\bar{k}$ we end up with $\bar{k}$ as a function of 
$s^{u}$. We can also obtain, in a similar manner, the relationship between average matric potential $\Psi$ and average saturation $s^{u}$. Following Lee et al. (2006) we select a Brooks and Corey (1964) type function to the fitted to the numerically obtained data:

$$
\begin{aligned}
\bar{k}\left(s^{u}\right) & =\bar{k}_{s}\left(s^{u}\right)^{\beta_{k}} \\
\Psi\left(s^{u}\right) & =\Psi_{b}\left(s^{u}\right)^{\beta_{\Psi}} \\
s^{u} & =\frac{\bar{\theta}}{\bar{\theta}_{s}}
\end{aligned}
$$

Given the assumed functional forms, the next step is to estimate the associated the REW scale effective parameters in Eq. (5), namely, hydraulic conductivity $\overline{k_{s}}$, bubbling pressure $\Psi_{b}$, and the exponents $\beta^{k}$ and $\beta^{\Psi}$.

Before we present the application of this approach to assess effective REW scale constitutive relations for the Weiherbach catchment it is worth to reflect the crucial assumption on the existence of a local equilibrium at that scale. The REW capillary pressure, which is obtained by volume averaging, should as a macroscopic state variable reflect the average pressure drop across the water/air interfaces in the pores at equilibrium. External disturbances e.g. due to infiltration of water will disturb this equilibrium. The water air interface will locally adapt its curvature to a new equilibrium, the disturbance will travel through the porous medium and the water air interfaces will subsequently react and establish a new local equilibrium. We call this process relaxation. The assumption of local equilibrium that is a precondition for the definition of a reasonable macroscopic capillary pressure at this scale (that indeed reflects the average of the microscopic states) makes only sense, if the relaxation time scale is much smaller than the time scale of external disturbances. It is intuitively clear that the relaxation time scale will increase with the size of the REW, and depend on the REV scale hydraulic properties and heterogeneity of the soil.

\section{Application to a headwater catchment}

\subsection{Study catchment and data base}

\subsubsection{Weiherbach catchment}

The application of the proposed theory is based on detailed data obtained within field observations in the Weiherbach valley (Zehe et al., 2001). The Weiherbach is a rural catchment of $3.6 \mathrm{~km}^{2}$ size situated in a loess area in the SouthWest of Germany. Geologically it consists of Keuper and Loess layers of up to $15 \mathrm{~m}$ thickness. The climate is humid with an average annual precipitation of 750-800 $\mathrm{mm} \mathrm{year}^{-1}$, average annual runoff of $150 \mathrm{~mm}_{\text {year }}{ }^{-1}$, and annual potential evapotranspiration of $775 \mathrm{~mm} \mathrm{year}^{-1}$. More than $95 \%$ of the total catchment area is used for cultivation of agricultural crops or pasture, $4 \%$ is forested and $1 \%$ is paved area. Crop rotation is usually once a year. Typical main crops are barley or winter barley, corn, sunflowers, turnips and peas;

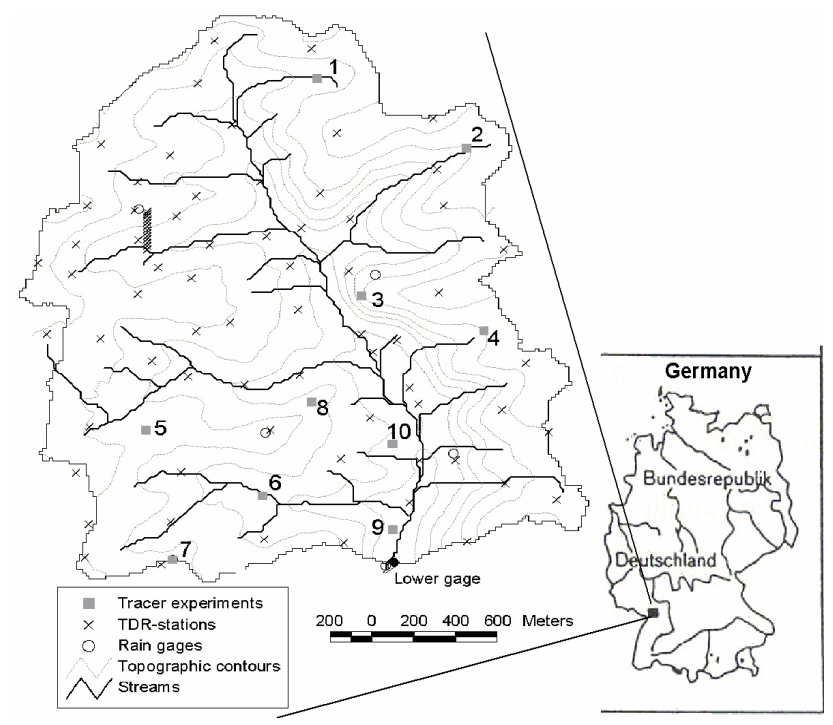

Fig. 1. Observational network of the Weiherbach catchment. Soil moisture was measured at 61 TDR stations at weekly intervals (crosses). Triangle indicates the stream gage. Topographic contour interval is $10 \mathrm{~m}$.

typical intermediate crops are mustard or clover. Ploughing is usually to a depth of 30 to $35 \mathrm{~cm}$ in early spring or early fall, depending on the cultivated crop. A few locations in the valley floor are tile drained to a depth of approximately $1 \mathrm{~m}$. However, the total portion of catchment area that is under tile drains is less than $0.5 \%$ of the total catchment. Detailed field observations (Zehe et al., 2001) in the Weiherbach catchment indicated that storm runoff is produced by infiltration excess overland flow.

Most of the Weiherbach hillslopes exhibit Loess soils. Preferential pathways in the Weiherbach soils are very apparent. The thickness of the Loess cover ranges from 15 to $30 \mathrm{~m}$. Preferential flow pathways are mainly a result of up to $1.5 \mathrm{~m}$ deep earthworm burrows (Zehe and Flühler, 2001; Ehrmann, 1996). The average depth of worm burrows in this catchment is around $60 \mathrm{~cm}$ (Zehe et al., 2001) with a maximum of up to $2 \mathrm{~m}$. As this is small compared to the thickness of the Loess layers, macropores almost never penetrate into the saturated zone in the Weiherbach catchment. Thus, the exchange between the unsaturated zone and the saturated zone, which is the major focus of our study, is determined by the properties of the subsoil matrix.

\subsubsection{Experimental database}

Figure 1 presents a map view of the observational network in the northern part of Weiherbach catchment. Rainfall input was measured in a total of 6 rain gauges and discharge was monitored at two stream gauges, all at a temporal resolution of $6 \mathrm{~min}$, and for a period of over 10 years. The gauged catchment areas are 0.32 and $3.6 \mathrm{~km}^{2}$. Soil moisture was measured 
Table 1. Average hydraulic properties for typical Weiherbach soils, determined from 200 undisturbed soil samples. The definition of parameters is after van Genuchten (1980) and Mualem (1976). Saturated hydraulic conductivity $k_{S}$, porosity $\theta_{S}$, residual water content $\theta_{r}$, air entry value $\alpha$, and shape parameter $\mathrm{n}$.

\begin{tabular}{lccccc}
\hline Soil & $\mathrm{k}_{s}$ & $\theta_{s}$ & $\theta_{r}$ & $\alpha$ & $\mathrm{n}$ \\
& {$[\mathrm{m} / \mathrm{s}]$} & {$[-]$} & {$[-]$} & {$[1 / \mathrm{m}]$} & {$[-]$} \\
\hline Calcaric Regosol & $(3.4 \pm 1.5) \times 10^{-6}$ & 0.46 & 0.06 & 1.5 & 1.36 \\
Colluvisol & $(4.1 \pm 2) \times 10^{-5}$ & 0.43 & 0.11 & 1.9 & 1.20 \\
\hline
\end{tabular}

at up to 61 locations at weekly intervals using two-rod TDR equipment that integrates over the upper 15,30 , and $45 \mathrm{~cm}$ of the soil. A soil map was compiled from texture information that was available on a regular grid of $50 \mathrm{~m}$ spacing. Most hillslopes exhibit a typical soil catena with moist but drained Colluvisols located at the foothills and dryer Calcaric Regosols located at the top and mid-slope sectors. The soil hydraulic properties of Weiherbach soils after van Genuchten (1980) and Mualem (1976) were measured in the laboratory using undisturbed soil samples along transects at several hillslopes, up to 200 samples per slope (Table 1, Schäfer, 1999). A digital elevation model with a grid spacing of $12.5 \mathrm{~m}$ represented the topography.

The macropore system, i.e. the number of earthworm burrows, was mapped at 15 sites in the catchment (compare Zehe and Flühler, 2001). The spatial pattern of soil macroporosity turned out to be closely related to the soil catena. The macroporosities tend to be small in the dry Calcaric Regosols located at the top and mid-slope regions, and larger in the moist and drained Colluvisols located at the valley bottoms (Zehe and Flühler, 2001; Zehe, 1999). This form of spatial organization may be explained by the habitat preferences of Lumbricus terrestris, which is the dominant deep digging earthworm species in that landscape (Ehrmann, 1996).

Curves representing the temporal development of LAI, plant height, biomass production, and root length were determined based on visual inspections of the main crops such as corn, wheat, oats, sunflowers, sugar beets, peas, mustard, and turnips as the basis for the evaporation module of CATFLOW. Further details on the measurement program are given in Zehe et al. (2001).

3.2 Hydrological model, and process- and landscapecompatible model structure

\subsubsection{Model structure and process formulation}

For our upscaling we employ the physically based, distributed hydrological model, CATFLOW (Maurer, 1997; Zehe et al., 2001). The model subdivides a catchment into a number of hillslopes and a drainage network. Each hillslope is discretized along the main slope line into a 2-dimensional vertical grid using curvilinear orthogonal coordinates. Each surface model element extends over the width of the hillslope. The widths of the surface elements may vary from the top to the foot of the hillslope. For each hillslope, evapotranspiration is represented using an advanced SVAT approach based on Penman-Monteith equation, which accounts for plant growth, albedo as a function of soil moisture, and the impact of local topography on wind speed and radiation. Soil water dynamics and solute transport are simulated based on the Richards equation in the mixed form, as well as a transport equation of the convection diffusion type. The hillslope module can simulate infiltration excess runoff, saturation excess runoff, reinfiltration of surface runoff, lateral water flow in the subsurface, return flow and solute transport.

However, in the Weiherbach catchment only infiltration excess runoff contributes to storm runoff and lateral subsurface flow does not play a major role at the event scale. What is important is the redistribution of near surface soil moisture in controlling infiltration and surface runoff. Surface runoff is routed on the hillslopes, fed into the channel network and routed to the catchment outlet based on the convection diffusion approximation to the 1-dimensional Saint-Venant equation. For reasons of brevity the model equations, which are now standard ones for most physically based models, are not presented here. For more details readers may refer to Maurer (1997), Zehe et al. (2001) and Zehe et al. (2005b).

Preferential flow is important for infiltration and generation of surface runoff in the Weiherbach catchment. In CATFLOW preferential flow is represented by an effective threshold approach, which is motivated by experimental findings of Zehe and Flühler (2001). Macropore flow starts when the relative saturation $S[-]$ at a macroporous grid point at the soil surface exceeds the threshold $S_{0}$. As the effect of active macropores in a model element is to increase the infiltration capacity, the hydraulic conductivity, $k^{B}$, of the element is increased as follows:

$$
\begin{aligned}
k^{B}(x, z) & = \begin{cases}k_{S}(x, z)+k_{S}(x, z) f_{m}(x, z) \frac{S-S_{0}}{1-S_{0}} \text { if } S \geq S_{0} \\
k_{S}(x, z) & \text { otherwise }\end{cases} \\
S(x, z) & =\frac{\theta(x, z)-\theta_{r}(x, z)}{\theta_{s}(x, z)-\theta_{r}(x, z)}
\end{aligned}
$$

where $k_{S}[1 / \mathrm{t}]$ is the saturated hydraulic conductivity of the soil matrix, $\theta_{s}\left[1^{3} 1^{-3}\right]$ and $\theta_{r}\left[1^{3} 1^{-3}\right]$ are saturated and residual soil moisture content, respectively, $\theta\left[1^{3} 1^{-3}\right]$ is the soil moisture, $x$ and $z$ are the coordinates along the slope line and the vertical. The macroporosity factor, $f_{m}[-]$, is defined as the ratio of the water flow rate in the macropores, $Q_{m}\left[1^{3} / \mathrm{t}\right]$, in a model element of area $A$ and the saturated water flow rate in the soil matrix $Q_{\text {matrix }}\left[1^{3} / \mathrm{t}\right]$. It is therefore a characteristic soil property reflecting the maximum influence of active preferential pathways on saturated soil water movement:

$f_{m}(x, z)=\frac{Q_{m}(x, z)}{Q_{\text {matrix }}(x, z)}$

For the Weiherbach soils we chose the threshold $S_{0}$ to be equal to 0.8 , which corresponds to the field capacity for the 
soils in the Weiherbach catchment. For relative saturation values above this threshold, free gravity water is present in the coarse pores of the soil, and this free water may percolate into macropores and thus may help start preferential flow. This plausible value of $S_{0}$ has been corroborated through model simulations performed at a number of spacetime scales in the Weiherbach catchment. Using the hillslope module of CATFLOW Zehe and Blöschl (2004) simulated preferential flow and tracer transport at several field plots in the Weiherbach catchment, which were in good agreement with observations. Simulations of tracer transport and water dynamics over an entire hillslope over a period of two years matched well the corresponding observations of a long-term tracer experiment at the hillslope scale (Zehe et al., 2001).

\subsubsection{Landscape- and process-compatible model structure} for the Weiherbach catchment

The Weiherbach catchment has been subdivided into 169 hillslopes and an associated drainage channel network, and each of the slopes was discretized into a 2-dimensional finite difference grid along the slope line. The surface model elements are 5-20 $\mathrm{m}$ wide and $10 \mathrm{~m}$ long. The width of the finite difference grid in the vertical direction varies from $5 \mathrm{~cm}$ close to the surface, to $25 \mathrm{~cm}$ at the lower boundary. The total soil depth represented by the model was $2 \mathrm{~m}$. The Manning roughness coefficients for the hillslopes and the channels were taken from a number of irrigation experiments performed in the catchment, as well as from the literature based on the current crop pattern (see Gerlinger et al., 1998; Zehe et al., 2001). For the hillslopes the following boundary conditions were chosen: free drainage at the bottom, seepage boundary conditions at the interface to the stream, atmospheric conditions at the upper boundary, and no flux boundary at the watershed boundary.

Due the existence of a "typical hillslope structure" with a typical soil catena and spatially organized macroporosity patterns in the Weiherbach catchment, we selected a simplified model structure that accounted only for the typical patterns of the hillslope, and neglected details of individual hillslopes. All hillslopes in the model catchment were given the same relative catena, with Calcaric Regosol in the upper $80 \%$ and Colluvisol in the lower $20 \%$ of the hill. The corresponding van Genuchten-Mualem parameters are listed in Table 1. Furthermore, all hillslopes were given the same spatial patterns of macroporosity. Measurements of macroporosity at 15 sites with $1 \mathrm{~m}^{2}$ sampling area in the Weiherbach catchment suggested high macropore volumes, typically of $1.5 \cdot 10^{-3} \mathrm{~m}^{3}$ in the moist Colluvisols at the hill foot, and low values of $0.6 \cdot 10^{-3} \mathrm{~m}^{3}$ at the top and mid-slope sectors (Zehe, 1999, cf. his Fig. 4.1). We chose the macroporosity factor to be $0.6 \times f_{m}$ at the upper $70 \%$ of the hillslope, $1.1 \times f_{m}$ at the mid-sector ranging from 70 to $85 \%$ of the hillslope, and $1.5 \times f_{m}$ at the lowest 85 to $100 \%$ of the slope length. The depth of the macroporous layer was assumed to be constant throughout the whole catchment and set at $0.5 \mathrm{~m}$. The unknown macroporosity factor, $f_{m}$, of the hillslopes was estimated by matching model predictions against observations from the largest observed rainfall-runoff event on record. A value of 2.1 turned out to be optimal (cf. Sect. 4.1 later for details).

Based on this model structure the water cycle in the Weiherbach catchment was simulated continuously over the period 21 April 1994 to 15 September 1995 with observed initial and boundary conditions (Zehe et al., 2001). After an initialization phase of approximately 30 days the model yielded, simultaneously, acceptable predictions of discharge with a Nash-Sutcliffe efficiency of 0.82 , and of evapotranspiration (ET) with a correlation of $R=0.92$. Furthermore, the model yielded reasonable predictions of soil moisture dynamics at 61 sites within the catchment. The average correlation between observed and simulated soil moisture was 0.65 at hilltop locations and 0.75 at the mid-slope and valley floor sectors. For reasons of brevity we omit figures on simulated and observed discharge, ET as well as on simulated and observed soil moisture values. Interested readers are referred to Zehe et al. (2005b) for these additional details.

Readers should keep in mind that the model structure presented here only accounts for typical variability exhibited within the catchment, i.e. representative hillslope soil catena and related structured patterns of macroporosity, as outlined in the previous section. Small-scale variability of soil hydraulic properties and the deviations in individual hillslopes from the assumed idealized soil pattern, have been neglected. Nevertheless, a major part of the variability of soil moisture, discharge and ET may already be explained by this landscape- and process-compatible model structure.

\subsection{Derivation of catchment scale state variables}

For derivation of time series of catchment scale state measures we employed the complete catchment model with the process and landscape compatible model structure and observed initial and boundary conditions during a 1.5 year long simulation of the complete hydrological process spectrum. By volumetric averaging, as defined in Eq. (1), we end up with a time series of catchment scale average soil moisture that should embed the fingerprint of the dominant patterns of soils and macropores inside and is at the same time consistent with the other hydrological processes observed in the catchment. To test this hypothesis we compare the following model structures during a simulation with observed boundary conditions covering the period from the 21 April 1994 to 15 September 1995:

- Landscape- and process-compatible (LPC) model structure as described in Sect. 3.2.2.

- No macropores (NOMAC): same pattern of soil types as above but with $f_{m}=0$ over the entire hillslope. 

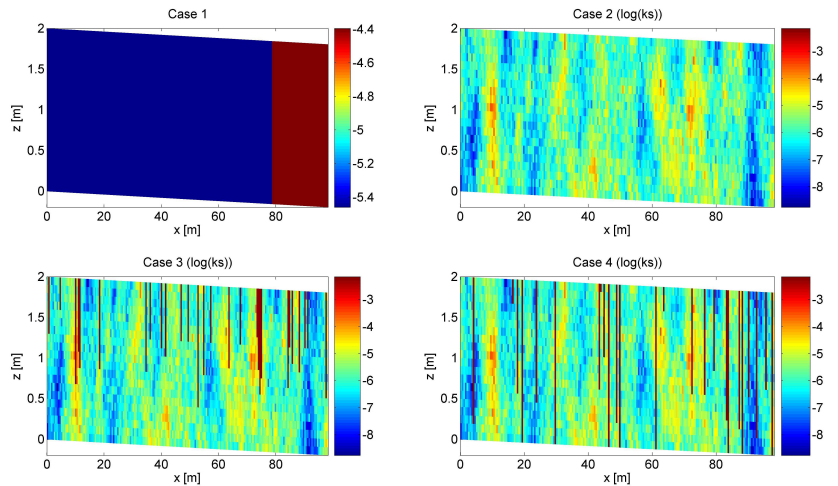

Fig. 2. Hillslope scale model structures for investigating the effect of small-scale heterogeneity on the numerical experiments.

- Disturbed macroporosity pattern (DM): same soil pattern as in the landscape- and process-compatible model structure, but a flipped macro-porosity pattern: $0.6 \times f_{m}$ at the lower $70 \%$ of the hillslope, $1.1 \times f_{m}$ from 15 to $30 \%$, and $1.5 \times f_{m}$ at the upper $15 \%$ of the total hillslope length. The value of $f_{m}$ remains equal to 2.1.

- Disturbed macroporosity and soils patterns (DMS): in addition to the macroporosity pattern the soil pattern was flipped in the same sense. The value of $f_{m}$ remained equal to 2.1 .

- Sand on Loess (SL): completely different model structure consisting of a sand layer of $1 \mathrm{~m}$ depth extending over the complete hillslope length, followed by Calcaric Regosol while macropores were neglected. The soil hydraulic parameters of the sand were taken from the pedotransfer function proposed by Carsel and Parrish (1988; see their Table 1).

For each of these model structures the average catchmentscale soil saturation and the average catchment-scale matric potential were derived after the 1.5-year simulation using Eq. (1).

\subsection{REW scale effective constitutive relations}

\subsubsection{Basic setup}

The characteristic structural element in the landscape- and process- compatible model is the hillslope with the typical patterns of soil types and the macroporosity factor. The idea was, therefore, to use a single hillslope for deriving the effective REW scale constitutive relations based on two series of simulated drainage and wetting experiments. The objective of the first series was to explore how local scale heterogeneity of ks and different populations of macropores that are consistent with our knowledge and findings in the Weiherbach affect the average fluxes and state variables when compared to simulations with the typical hillslope. Hence, the basic hillslope catena of soil types was invariant but superimposed with matrix and macropore heterogeneity during this exercise. Within the second series we neglected local scale heterogeneity and compared several patterns of soil types with the typical pattern of soil types and macropores.

In the wetting case we started with an initial saturation of 0.3 and impose a constant matric potential of $0 \mathrm{~m}$ (saturation) at the lower boundary. Along the remaining boundaries there was a zero flux boundary condition. In the drainage case we started at a saturation of 0.99 and imposed an increasing suction head at the lower boundary (up to $-6000 \mathrm{~m}$ pressure suction head). The total depth of the simulation domain was $2 \mathrm{~m}$, and the simulation period was 2 years. The wetting case is equivalent to capillary rise from the saturated into the unsaturated zone the drainage case is equivalent to recharge.

\subsubsection{Effect of stochastical heterogeneity on the numerical experiments}

In this part of the study we compared four different hillslope structures. In all cases the hillslope soil body that was $100 \mathrm{~m}$ long and $2 \mathrm{~m}$ deep was discretized into elements of $10 \mathrm{~cm}$ depth and $10 \mathrm{~cm}$ width. The topography did in this case not correspond to the average topography of a Weiherbach hillslope (Fig. 2):

- Case 1: We adopt the typical pattern of soil types with Calcaric Regosol in the upper part $80 \%$ and Colluvisol in the lower 20\%; the corresponding values of the saturated hydraulic conductivity are given in Table 1 (after Schäfer, 1999).

- Case 2: We adopt the same soil pattern as in case 1 which is superimposed by a stochastic field of saturated hydraulic conductivities generated with the turning bands method. Following Zehe and Blöschl (2004) and Schäfer (1999), we set the total variability as one order of magnitude (compare their Table 3). The unknown ranges in the vertical and the lateral directions were estimated to $3 \mathrm{~m}$ and $10 \mathrm{~m}$ respectively, and the nugget was set to zero.

- Case 3: Here a population of macropores that is typical for the Weiherbach catchment superimposes the hillslope model structure of case 2. The macropore system is modelled as a Poisson point process (Beven and Clarke, 1986). The necessary data, i.e., the average number of macropores per unit area, the average and the variance of the macropore depth, as well as the hydraulic capacity of worm burrows for conducting water are taken from Table 7 (Zehe and Blöschl, 2004).

- Case 4: Here a population of macropores that is not typical for the Weiherbach catchment superimposes the hillslope of case 2. The average number of macropores per unit area, the variance of the macropore depth 
as well as the hydraulic capacity of worm burrows for conducting water are the same as in case 3. However, the average macropore length has been increased from $80 \mathrm{~cm}$ to $150 \mathrm{~cm}$ such that some of the macropores penetrate through the lower boundary of the simulation domain. This corresponds to the case where some macropores link soil surface directly to the saturated zone

As we did account for preferential pathways in an explicit manner through local increase of the saturated hydraulic conductivity $K_{S}$-values of up to $10^{-2} \mathrm{~m} / \mathrm{s}$, the simplified threshold approach for enhanced infiltration due to active macropores was switched off (Fig. 2).

We admit that the heterogeneous fields might not look like what one would expect in terms of soil heterogeneity at the hillslope scale. By selecting a spherical variogram and a range of $10 \mathrm{~m}$ we assume that the correlation length of the saturated hydraulic conductivity is smaller than the extent of the hillslope and that the field is intrinsic. However, the generated fields and especially the macropores are consistent with our findings (Schäfer, 1999; Zehe et al., 2001) and what is known for worm burrows of Lumbricus terrestris (Shipitalo and Butt, 1999).

3.4.3 Effect of different patterns of soil types and macroporosity on derived constitutive relations

To demonstrate that hillslopes different from that of the landscape- and process-compatible model structure yield clearly different REW scale soil hydraulic functions, the numerical experiments were carried out for the hillslope structures different from those introduced in Sect. 3.3:

- Landscape- and process-compatible hillslope

- Hillslope with deep macropores: the hillslope has the same patterns of soil types and macroporosity as in the case of the landscape- and process-compatible hillslope, but the depth of the macroporous layer equals the depth of the simulation domain.

- Hillslope with Loess soil: the entire hillslope consists of Calcaric Regosol, $f_{m}$ was set to 1.6.

- Hillslope with Colluvisol soil: the entire hillslope consists of Colluvisol, $f_{m}$ was set to 1.6.

- Hillslope with sandy soil: the entire hillslope consists of sand, $f_{m}$ was set to 0 .

For each simulated case we computed the REW scale hydraulic conductivity from the average flow from across the lower boundary using Eq. (3). By computing the average hillslope scale soil moisture and matric potential we end up with a) the effective hillslope scale hydraulic conductivity as a function of the average hillslope scale water saturation as well as b) the hillslope scale water saturation as a function of
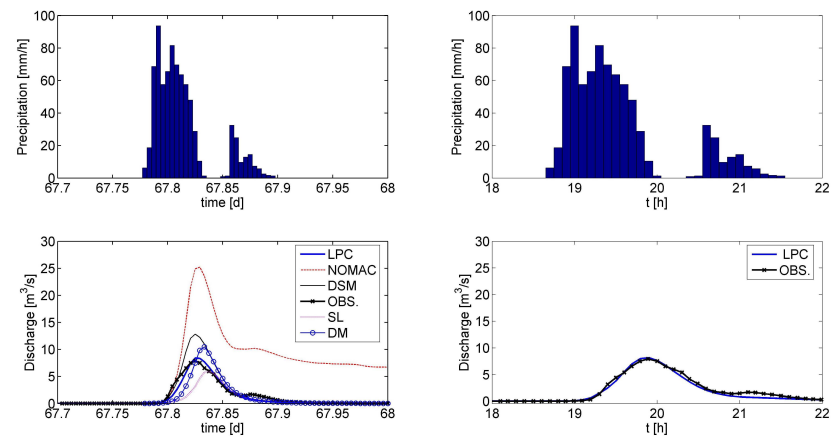

Fig. 3. The lower right panel compares discharges observed at the catchment outlet with the simulation from the landscape- and process-compatible model structure (LPC) for the largest rainfall runoff event (27 June 1994). The lower left one compares catchment scale runoff responses simulated for catchment models with the different structures.

the average hillslope scale matric potential. In the last step the parametric functions defined in Eq. (5) were fitted to the data using the curve fitting toolbox of MATLAB. Hillslope topography was taken from a typical hillslope in the Weiherbach catchment.

\section{Results and discussion}

\subsection{Catchment scale state variables}

In order to illustrate that the model structures different from the landscape- and process compatible one yielded during the long-term simulations produce strongly different runoff responses at the catchment scale, Fig. 3 compares them for the largest rainfall event that occurred on 27 June 1994. Runoff response simulated with the landscape- and processcompatible model is in good agreement with the observation at the catchment outlet (lower right panel). In contrast, the runoff response produced by other catchment models perform clearly worse. Sand on top of the Loess soil yields a retarded and reduced runoff response, which stems from subsurface storm flow on the Loess horizon that exists at $1 \mathrm{~m}$ depth. It is remarkable that the rearrangement, i.e. the flipping of the spatial patterns of soil types and/or macroporosity, is already sufficient to yield significantly different rainfall-runoff behaviour. Flipping the macroporosity pattern causes a stronger runoff response, as the infiltration capacity of soils near the stream is now, even in the case of active macropores, lower than in the case of the landscape- and process-compatible model structure. Flipping both the spatial soil and macroporosity patterns yields an even stronger runoff response, as the saturated hydraulic conductivity of the Calcaric Regosol is only one tenth of the saturated hydraulic conductivity of the Colluvisol. 

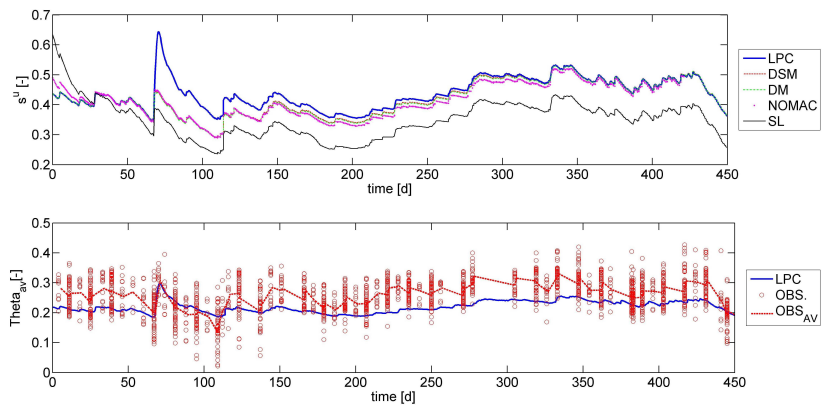

Fig. 4. Average catchment-scale soil saturation (top panel) for the different model structures. The lower panel shows the average catchment scale soil moisture (according to Eq. 1) simulated with the landscape- and process-compatible model structures as well as the observed soil moisture values from $45 \mathrm{~cm}$ TDR rods available at up to 61 locations (circles) and their area-weighted average (dashed red line). The blue solid line is marks in both panels the time series simulated with the landscape- and process-compatible model.
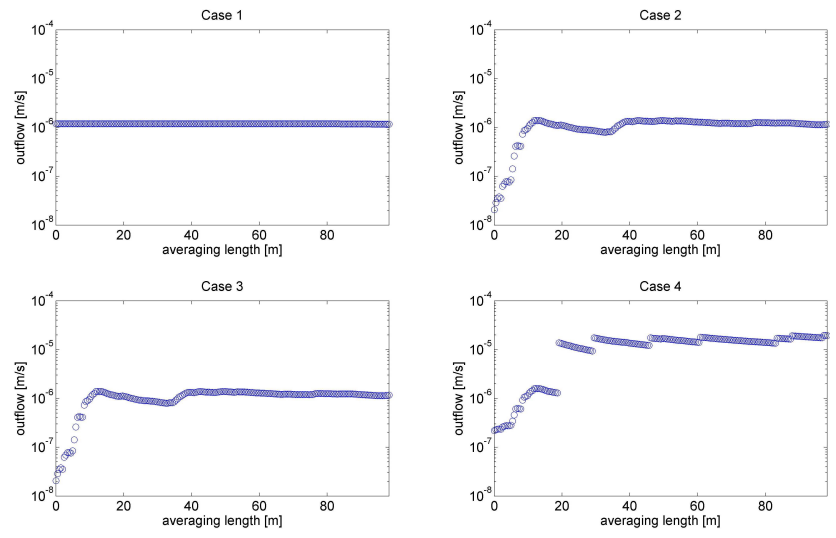

Fig. 5. Outflow averaged over different fractions of the lower boundary, starting at the lower left corner (averaging length is zero) up to the full extent (averaging length is $100 \mathrm{~m}$ ).

\subsection{Hillslope scale drainage and wetting experiments}

\subsubsection{Effect of subscale heterogeneity}

Figure 4 (upper panel) shows the time series of the catchment-scale average soil saturation $s^{u}$. The time series derived from the landscape- and process-compatible model structure clearly differs from those derived from the remaining model structures. Major differences occur during stronger rainfall events, e.g. on day 67 (27 June 1994), and persist for more than 100 days. But there are also smaller differences between the time series produced by the flipped spatial patterns of soils and/or macroporosity. As expected, the catchment scale soil saturation for the sand on Loess catchment exhibits the lowest values throughout the simulation period. These series of averaged soil saturation values show clearly and unambiguously that the fingerprint of within-catchment heterogeneities of soils and macropores on soil moisture dynamics does not vanish when we move to the next higher scale. As the runoff response simulated with the landscape- and process-compatible model is compatible with the observations (Nash-Sutcliffe efficiency of 0.82 compared to the other model structures which yield values that are smaller than 0.3 ), the series of averaged soil saturation is process consistent with the observed runoff response!

Furthermore, Fig. 4 also shows (lower panel) that the time series of catchment-scale average soil moisture $\theta_{a v}$ simulated by the landscape- and process-compatible model structure falls in the range of the observed soil moisture values, measured with $45 \mathrm{~cm}$ long TDR rods at up to 61 measurement locations. As $\theta_{a v}$ is averaged over a depth of $2 \mathrm{~m}$, the time series is, as expected, smoother than the observations. It should be noted here that the time series of the upscaled catchment scale soil moisture are not just simply the arithmetic averages of the observations.
Figure 5 presents, as an example, the outflow in the case of the numerical drainage experiment averaged over different parts of the lower boundary at the first time step. An averaging length of zero means that we just took the outflow at the outer left node, increasing the averaging length to $100 \mathrm{~m}$ indicates that outflow is averaged over an increasing fraction of the hillslope. For the cases 1 to 3 the average outflow remains constant after an averaging length of $40 \mathrm{~m}$, which corresponds to 4 times the horizontal range of the $K_{s}$-pattern. Furthermore, it can be seen that macropores, so long as they do not penetrate through the lower boundary, do not affect the outflow at the lower boundary (compare lower right panel to other panels). For case 4, where macropores directly penetrate through the lower boundary, outflow does not reach a really constant value even when averaged over the whole lower boundary. Every time, we include a macropore that penetrates through the lower boundary into the averaging process, this causes a clear change in the average outflow. However, as case 4 is not typical for the Weiherbach catchment we conclude that the exchange between the unsaturated and saturated zones in the Weiherbach catchment is not affected by macropores, but is controlled by hydraulic properties of the soil matrix.

For case 1 but also for the cases 2 and 3 the exchange flux appear to be constant after at an averaging length scale of approximately four times the correlation length remain constant. We conclude that for this specific type of heterogeneity that is consistent with our findings in the Weiherbach a typical hillslope of $100 \mathrm{~m}$ length is sufficient for conducting numerical for deriving effective REW scale constitutive relations (instead of performing numerical experiments with the full catchment model). However, one should 

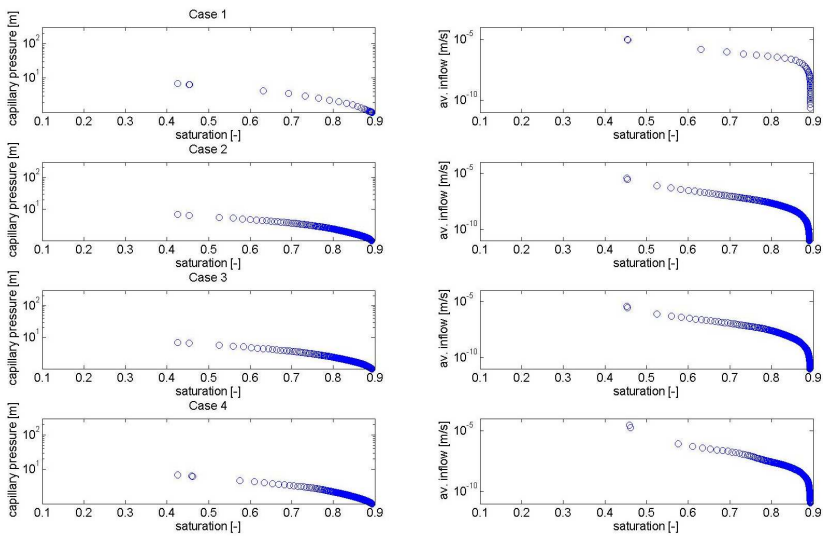

Fig. 6. Capillary pressure - saturation relations (left panels) and inflow - saturation relation (right panels) obtained within the numerical wetting experiments.

not conclude that in general it is sufficient to average over 4 times the correlation length to end with an effective homogeneous medium. One could even think of fat tailed media with much stronger heterogeneity and strong connectivity of extreme ks-values, where average outflow does never become constant.

Figure 6 and 7 present the capillary pressure-saturation relations and inflow/outflow characteristics obtained within the numerical wetting/drainage experiments respectively. The effective capillary pressure-saturation relations of the wetting experiment look for all cases pretty similar expect at the lower end of the investigated saturation values, where case 4 appears to be different (Fig. 6 left panels). This different behaviour at low saturation values becomes much clearer in the drainage case. At low saturations the homogeneous case1 drains "more easily" than the other cases, which means that effective water retention is stronger in the heterogeneous media. This maybe explained by areas with low conductivity that are located close to the lower boundary (compare Fig. 2), and reduce the average drainage velocity especially at low saturations.

By comparing Fig. 6 and 7 we must state that the effective soil water characteristics are hysteretic in all cases. This is interesting to note, as Zhang and Savenije (2005) used a non-hysteretic effective soil water characteristic within their successful application of REWASH to the Geer River. Also Lee et al. (2006, this issue) obtained good simulation results within an application of the CREW model to the Weiherbach catchment when using a non-hysteretic effective soil water characteristic. When investigating the time series of the saturation $\mathrm{s}^{u}$ in the unsaturated zone obtained during the latter simulation, it becomes clear $s^{u}$ covers a narrow range between 0.35 and 0.5 during the simulation period, furthermore daily changes are of order 0.001 (compare their Fig. 9). This is plausible, as under natural boundary conditions, net infiltration/exfiltration at the upper and net recharge/capillary rise
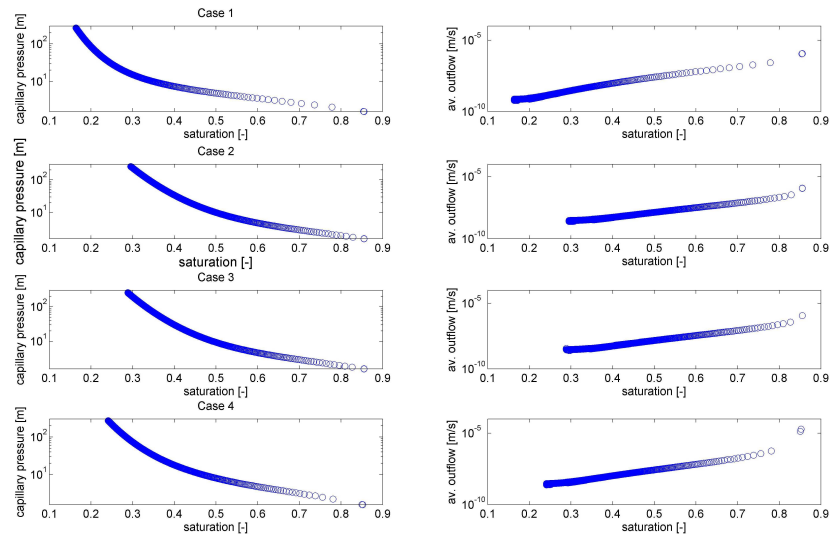

Fig. 7. Capillary pressure - saturation relations (left panels) and outflow - saturation relation (right panels) obtained within the numerical drainage experiments.
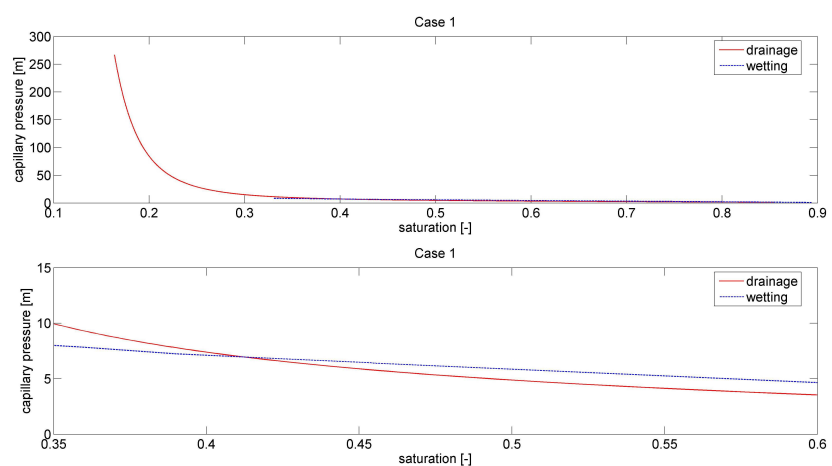

Fig. 8. Capillary pressure - saturation relation for Case 1 (typical hillslope) for the wetting and drainage experiment, the lower panel is zoomed to the range of saturation values that were covered during the one years simulation with CREW.

across the lower boundary occur at the same time, which explains the small changes in saturation and the low range of saturations. It can be seen in Fig. 8 (lower panel) that the differences between the wetting and drainage curve in this narrow range of saturations is quite small. It seems that the use of a non-hysteretic curve for wetting and drainage within this narrow range didn't cause serious errors. Therefore, we derived non-hysteric effective soil water characteristics based on the simulated drainage experiments as presented. However, in general one should not conclude, that hysteretic behaviour could be neglected, especially not in drier climates, where $s^{u}$ could drop to much smaller values.

\subsubsection{Hillslope scale constitutive relations}

Figure 9 presents the results of the simulated hillslope scale drainage experiments for the landscape- and processcompatible hillslope (upper left two panels), the case of long macropores (upper right two panels), for the Loess hillslope 

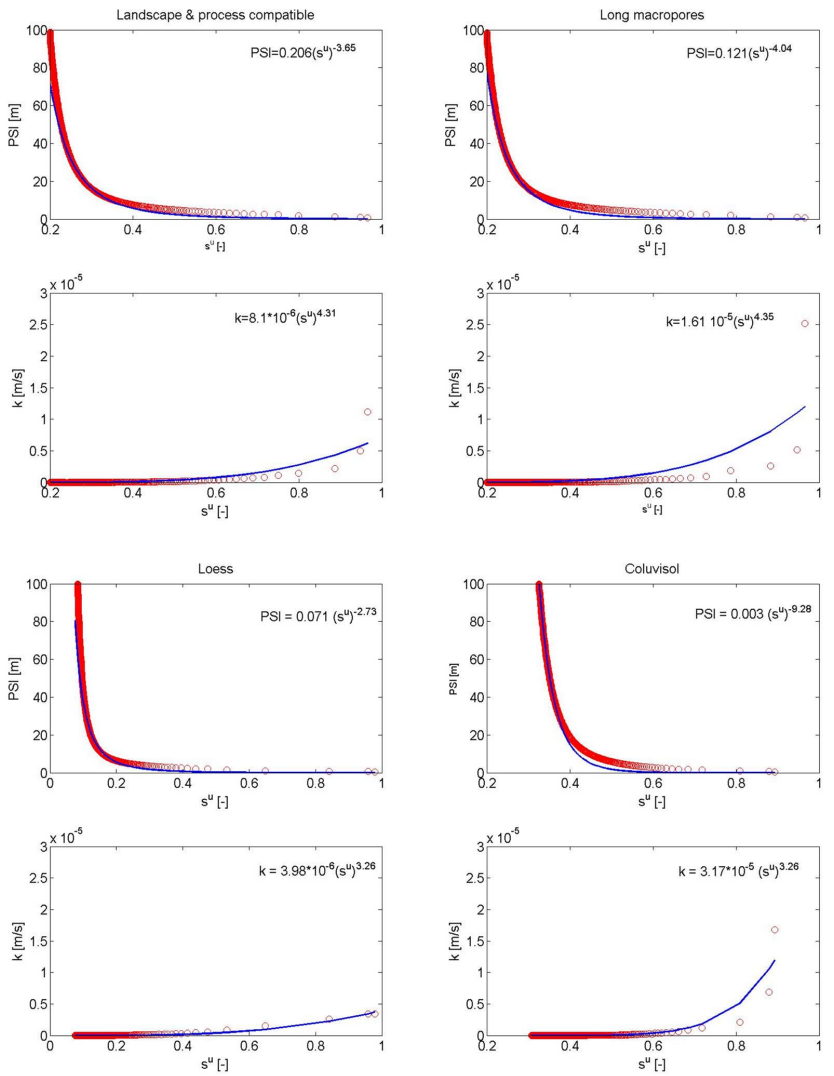

Fig. 9. Hillslope/REW scale soil hydraulic functions derived from simulated drainage experiments for the landscape- and processcompatible hillslope (upper 2 left panels), a hillslope with same spatial pattern of soils and macropores, but where the macropores reach continuously to the lower boundary of the modelling domain (upper 2 right panels), for a homogeneous hillslope with a loess soil (lower 2 left panels, REV scale hydraulic parameters given in Table 1) and a homogeneous hillslope with a Coluvisol soil (lower 2 right panels). The $95 \%$-confidence limits as well as the $\mathrm{R}^{2}$ of the fits are given in Table 2.

(lower left two panels) and the Coluvisol hillslope (lower right two panels). In addition, Table 2 lists the estimated hydraulic parameters (according to Eq. 5), which are clearly different for the different hillslope structures, as well as the 95\% confidence limits (obtained with the MATLAB curve fitting tool box). The landscape- and process-compatible hillslope and the one with long macropores yield similar effective hillslope scale water retention curves (according to Eq. 3 and Eq. 5). However, since the longer macropores that reach continuously to the lower boundary of the model domain cause a faster drainage at saturations larger than 0.8 , the bubbling pressure $\Psi_{b}$ is therefore $50 \%$ smaller in this case. The faster drainage results also in an effective hillslope scale saturated hydraulic conductivity, which at $1.61 \times 10^{-5} \mathrm{~ms}^{-1}$, is twice as high as for the landscape- and process-compatible hillslope. However, the fit of the effective hydraulic conduc- tivity curve, in the case of the long macropores, with an $\mathrm{R}^{2}$ of 0.51 , is not really satisfactory. This is due to the very fast drop of the hydraulic conductivity at high saturations, because of the threshold approach adopted for the onset of macropore flow in CATFLOW (Eq. 6).

It is interesting to note that the catchment scale saturated hydraulic conductivity estimated for the landscape- and process-compatible hillslope is, at $8.1 \times 10^{-6} \mathrm{~ms}^{-1}$, close to the area weighted average of the average REV scale values given in Table 1 (note the this hillslope has $80 \%$ Calcaric Regosol and 20\% Colluvisol). Note the landscape- and process-compatible hillslope structure in this case is very simple: two layers with their interfaces parallel to the direction of flow. In the case of saturated flow it is easy to show that the effective conductivity of such a structure is the area weighted average (Jury and Horton, 2004). Hence, the approach yields results that are consistent with the asymptotic case of weakly heterogeneous media. In stronger heterogeneous media with layers the average $K_{S}$-value will be of course a bad guess for the REW scale parameter.

The exponent $\beta^{\Psi}$ of the water retention function is a measure for the capillary forces that act on water in the upscaled textural medium. The higher clay content and the larger amount of fine pores in Colluvisol are therefore reflected in a value of $\beta^{\Psi}$ which is 4 times larger than that of the Loess hillslope. As expected $\beta^{\Psi}$ of the landscape- and processcompatible hillslope, at 3.65, falls between the values derived for the Loess and the Colluvisol hillslopes. Note in addition that the bubbling pressure derived for the Loess and the Colluvisol hillslopes (Table 2) are more than one order of magnitude smaller than the inverse of the corresponding $\alpha$ values of the REV-scale parameter sets given in Table 1. Hence, the bubbling pressures differ strongly from their REV scale analogues.

\section{Summary and conclusions}

The main findings of the present study may be condensed into the following three points: firstly, the representation of the dominant spatial patterns of soil heterogeneity and macroporosity in the process model CATFLOW, which are typical for this Loess area of Germany, is sufficient to explain the major aspects of the observed discharge-, ET- and soil moisture dynamics in a typical catchment in this region. We want to stress here in this context that, to achieve this result, it was not necessary to account for the exact soil catena and the small-scale variability of soil properties at the individual hillslopes. The model is nevertheless landscape specific since it only accounts for the dominant heterogeneities that are and typical for this Loess area, and process compatible, since it explains a large part of the observed dynamics of the different state variables.

Secondly, we derived a time series of catchment-scale average soil saturation by averaging the output of the 
Table 2. Parameters of the REW scale soil hydraulic functions (compare Eq. 5) derived for the different model structures (defined in Sect. 3.3.2): Average hydraulic conductivity $\overline{k_{s}}$, exponent of the unsaturated hydraulic conductivity curve $\beta^{k}$, average REW scale bubbling pressure $\Psi^{b}$ as well as the exponent of the water retention function $\beta^{\Psi}$. The values in brackets give the $95 \%$ confidence limits.

\begin{tabular}{cccccc}
\hline Parameter & 1 & 2 & 3 & 4 & 5 \\
\hline$\overline{k_{s}}$ & 8.1 & 16.1 & 3.98 & 31.7 & 70.8 \\
{$\left[10^{-6} \mathrm{~m} / \mathrm{s}\right]$} & {$[3.76,11.2]$} & {$[2.2,26.0]$} & {$[2.01,5.99]$} & {$[3.27,60.2]$} & {$[63.6,71.1]$} \\
$\beta^{k}$ & 4.31 & 4.35 & 3.26 & 8.57 & 2.67 \\
{$[-]$} & {$[1.05,7.57]$} & {$[1.21,9.86]$} & {$[3.40,7.92]$} & {$[2.32,14.8]$} & {$[2.60,2.93]$} \\
$\mathrm{R}_{k}^{2}$ & 0.82 & 0.5 & 0.78 & 0.81 & 0.81 \\
$\Psi^{b}$ & 0.206 & 0.121 & 0.071 & 0.0031 & $4.310^{-5}$ \\
{$[\mathrm{~m}]$} & {$[0.197,0.220]$} & {$[0.11,0.133]$} & {$[0.062,0.080]$} & {$[0.0023,0.0032]$} & {$[3.9,4.8] \times 10^{-5}$} \\
$-\beta^{\Psi}$ & 3.65 & 4.03 & 2.73 & 9.28 & 5.15 \\
{$[-]$} & {$[3.70,3.50]$} & {$[4.10,3.97]$} & {$[2.79,2.07]$} & {$[9.34,9.28]$} & {$[5.18,5.12]$} \\
\hline $\mathrm{R}_{\Psi}^{2}$ & 0.89 & 0.51 & 0.97 & 0.99 & 0.99 \\
\hline
\end{tabular}

1. Landscape- and process-compatible hillslope

2. Hillslope with deep macropores

3. Hillslope with Loess soil

4. Hillslope with Colluvisol soil

5. Hillslope with loamy sandy

landscape- and process-compatible model. The fingerprints of the within-catchment heterogeneity of soils and macropores on the average soil moisture dynamics do not vanish when we move to the next higher scale. The time series of catchment-scale average soil moisture is physically consistent with a distributed set of observations inside the catchment as well as with the typical structures in this catchment. It can be deemed as best guess how the unknown real average soil moisture in the Weiherbach catchment developed during this period and capable of reflecting and embedding within it the fingerprints of the dominant within-catchment heterogeneities on subsurface dynamics at the REW-scale. Therefore, it represents a suitable target data set for testing subsurface components of meso-scale hydrological models, as shown in the accompanying paper by Lee et al. (2006). We consider this approach of dynamical upscaling to be much more appropriate for the upscaling of local observations than, for example, geo-statistical approaches, because it maximises the use of all available physically-based process understanding and landscape specific information through the application of spatially explicit process models for interpolations within the catchment.

Thirdly, within the simulated hillslope scale drainage experiments, we derived effective hillslope-scale soil hydraulic functions for different model structures. For the investigated weak heterogeneities, that are compatible with our findings in the Weiherbach catchment, it was shown that the effect of small scale statistical heterogeneities on flow across the lower hillslope boundary averaged out after a length of approximately four times the range of the hydraulic conductivity field. It was shown furthermore that macropores/worm burrows of a typical depth had no influence on the flow across the lower boundary of the unsaturated zone. However, as stated in Sect. 4.2.1 this results is specific to the type and degree of heterogeneities investigated here and cannot be generalised to media with stronger heterogeneities and connected extreme values.

The obtained soil water characteristics turned out to be clearly hysteretic (which is consistent with findings of Mantoglou and Gelhar, 1987). Nevertheless, we derived a nonhysteretic curve based on the typical landscape- and processcompatible hillslope, which turned out to be sufficient for a successful application of CREW to the Weiherbach catchment (Lee et al., this issue). This is because during the one year simulation the saturation $s^{u}$ of the unsaturated zone covered a narrow range of values ranging from $0.35-0.5$, were hysteretic behaviour could be neglected as first order approximation. Again, this should not be generalised. Hysteretic behaviour could become important in drier climates, where $s^{u}$ could to drop to much lower values. On the other hand it might be a good first guess to neglect hysteretic behaviour in humid catchments, as supported by the study of Zhang and Savenije (2005) in the Geer River.

A sensitivity analysis showed furthermore that patterns of soil types and macroporosity different from the one that is typical for the Weiherbach yielded clearly different effective hillslope scale soil water characteristics. The related differences were consistent with the REV scale soil pore size spectra. When fitting two-parameter functions to the obtained effective REW scale soil water characteristics, we found that different hillslope structures yielded clearly different parameters. Hence, the different parameters obtained for 
the different model structures embed within them the fingerprints of subscale soil patterns and structures on water flow in the unsaturated zone to the next higher scale, in the sense of Vogel and Roth (2003).

Lee et al. (2005) employed a simpler approach for deriving effective constitutive relations for the Weiherbach catchment. Within their approach the authors used the complete catchment model and the observed boundary conditions instead. The authors simply averaged the unsaturated hydraulic conductivity of the model structure to obtain a catchment scale hydraulic conductivity curve. The parameters obtained with the latter approach did not yield a reasonable performance of the CREW model in the Weiherbach catchment as shown by Lee et al. (2006 this issue). Hence, in their study the authors had to calibrate the constitutive relations for a model structure consisting of just 3 REWs, which resulted in a simulated discharge time series with a Nash-Sutcliffe efficiency of 0.82 . The reader should note that the calibrated parameter values obtained by Lee et al. (2006, this issue) are very close to the values we obtained a priori for the landscape- and process-compatible model. At the same time, the time series of the unsaturated zone saturation simulated with the CREW model matched very well the time series of catchment-scale average soil saturation derived from the landscape- and process-compatible model structure. This correspondence hints clearly that the presented upscaling approach yields useful target measures and effective constitutive relations for hydrological models based on the REW approach, at least for the application of CREW in the Weiherbach catchment.

However, it would be silly to claim that the problem of assessing effective REW scale material properties is now solved. Within the present study we dealt with the question whether we can find an ergodic length scale for the Weiherbach so that we can assess the minimum extend of the REW scale. But we did not investigate whether the assumption of local equilibrium does really hold at that scale, i.e. whether the REW scale capillary pressure is a reasonable state variable that represents the average of the equilibrium capillary pressures in the pore space. It is clear that this assumption becomes more and more problematic with increasing size of an REW in the lateral and an increasing depth of the unsaturated zone (as stated in Sect. 2). Hence, ergodicity and the assumption of a local equilibrium are concurring conditions in the sense that fulfilling the one could mean to violate the other. We might at least overcome the problem for the vertical when allowing a vertically distributed representation of the unsaturated zone. However, this goes back to fundamentals of REW theory and is beyond the scope of this paper and is left for future research. The assumption of a local equilibrium that allows lateral averaging of capillary pressures over a large extent should be investigated within distributed numerical experiments using a homogeneous hillslope but with spatially distributed infiltration in the future. However, these thoughts show clearly that we have to be much more critical with our assumption, even if they are based on well-established concepts as the REW approach. What we urgently need is a much more consistent framework of upscaling that makes use of "everything" we have (including REV scale distributed models), to solve the closure problem and we hope we could suggest a useful concept for that.

\subsection{Long term vision of closure and PUB}

But even if we succeed in deriving closure relations and setting up the CREW model for a catchment of interest such as the Weiherbach catchment as shown in Lee et al. (2006, this issue), the crucial question is: To which extent are these closure relations unique and only valid in the particular catchment they were derived for? For the model structure for the simulated wetting and drainage experiments we used knowledge/understanding about typical features of the Weiherbach catchment such as the knowledge how the catena looks like and that earthworm burrows do not penetrate into the saturated zone. Will we have to repeat this very laborious derivation of closure relations at each individual catchment? Or do these closure relations capture the typical hydrological functioning of landscape compartments? In this case a REW with a certain set of closure relations would be a functional unit for building meso-scale models in a landscape, which allow the setup of models that need less calibration and hopefully a lower structural error.

To support the second point of view we finally employ the pattern-process paradigm and the idea of potential natural states from theoretical ecology (Watt, 1947; Turner, 1989; Turner and Gardner, 2001). The essence of the patternprocess paradigm is that similarity of patterns (in soils, vegetation and subsurface structures) is an indicator of similarity of processes (Grayson and Blöschl, 2000). Furthermore, the potential natural state of a landscape is an equilibrium state due to a balance of "external" disturbances and "internal" forces. This balance is reflected in typical, spatially organized patterns of vegetation, soils and subsurface structures. As hydro-climatic processes in a specific geological environment and climate have formed these patterns, we argue that these typical patterns in turn cause similarity of hydrological processes. We postulate, therefore, the existence of a typical process spectrum/hydrological functioning to be a generic feature of a landscape. We believe therefore that a set of typical closure relations exists for each landscape that may encapsulate this typical hydrological functioning, in the sense similar to typical soil hydraulic functions being applicable for different soil types. However, this hypothesis remains to be tested within a future application of the CREW model with the closure relations derived within this study and the study of Lee et al. (2006) to a larger catchment such as the Sulm catchment in the same Loess area in Germany. This exploration is currently in progress and results are expected in the near future. 
Acknowledgements. We'd like to thank the reviewers K. Beven and J. Zhu for their valuable reviews as well as the editor K. Roth for his comments that contributed to strongly improve this manuscript.

Edited by: K. Roth

\section{References}

Attinger, S.: Generalized coarse graining procedures for flow in porous media, Comput. Geosci., 7, 253-273, 2003.

Binley, A., Elgy, J., and Beven, K.: A physically based model for heterogeneous hillslopes. 1 Runoff production, Water Resour. Res., 25(6), 1219-1226, 1989a.

Binley, A., Beven, K., and Elgy, J.: A physically based model for heterogeneous hillslopes. 2 Effective hydraulic conductivities, Water Resour. Res., 25(6), 1219-1226, 1989 b.

Brooks, R. H. and Corey, A. T.: Hydraulic properties of porous media, Colorado State Univ., Hydrology Paper No. 3, 27pp, 1964.

Carsel, R. F. and Parrish, R. S.: Development of joint probability distributions of soil water retention characteristics, Water Resour. Res., 24(5), 755-769, 1988.

Dagan, G.: Statistical theory of groundwater flow and transport: pore to laboratory, laboratory to formation and formation to regional scale, Water Resour. Res., 22(9), 120-134, 1986.

Ehrmann, O.: Regenwürmer in einigen südwestdeutschen Agrarlandschaften: Vorkommen, Entwicklung bei Nutzungsänderung und Auswirkung auf das Bodengefüge, Hohenheimer Bodenkundliche Hefte Nr. 35. University of Hohenheim, Stuttgart, Germany, 1996.

Gelhar, L. W.: Stochastic Subsurface Hydrology, Prentice Hall, 1993.

Gerlinger, K.: Erosionsprozesse auf Lößböden: Experimente und Modellierung. Dissertation at the Institute of Water Resources Planning and Rural Engineering, University of Karlsruhe, Germany, 1997.

Grayson, R. B. and Blöschl, G. (Eds.): Spatial Patterns in Catchment Hydrology: Observations and Modelling, Cambridge University Press, Cambridge, UK, 404 pp, 2000.

Jury, W. and Horton, R.: Soil Physics, John Wiley \& Sons, 2004.

Lee, H., Sivapalan, M., and Zehe, E.: Representative Elementary Watershed (REW) approach, a new blueprint for distributed hydrologic modelling at the catchment scale: the development of closure relations, in: PREDICTING UNGAUGED STREAMFLOW IN THE MACKENZIE RIVER BASIN: TODAY'S TECHNIQUES \& TOMORROW'S SOLUTIONS, edited by: Spence, C., Pomeroy, J. W., and Pietroniro, A., Canadian Water Resources Association (CWRA), Ottawa, Canada, 165-218, 2005.

Lee, H., Sivapalan, M., and Zehe, E.: Predictions of rainfall-runoff response and soil moisture dynamics in a microscale catchment using the CREW model, Hydrol. Earth Syst. Sci. Discuss., 3, 1667-1743, 2006,

http://www.hydrol-earth-syst-sci-discuss.net/3/1667/2006/.

Liu, Z. and Todini, E.: Towards a physically based rainfall runoff model, Hydrol. Earth Syst. Sci., 6, 859-881, 2002, http://www.hydrol-earth-syst-sci.net/6/859/2002/.

Liu, Z., Martina, M., and Todini, E.: Flood forecasting using a fully distributed physically based model: Application of the TOPKAPI model to the uppter Xixian Catchment, Hydrol. Earth Syst.
Sci., 9, 347-365, 2005,

http://www.hydrol-earth-syst-sci.net/9/347/2005/.

Lunati, I., Attinger, S., and Kinzelbach, W.: Macrodispersivity for transport in arbitrary nonuniform flow fields: Asymptotic and pre-asymptotic results, Water Resour. Res., 38(10), 1187, doi:10.1029/2001WR001203, 2002.

Mantoglou, A. and Gelhar, L. W.: Effective hydraulic conductivities of transient unsaturated flow in stratified soils, Water Resour. Res., 23(1), 57-67, 1987.

Maurer, Th.: Physikalisch begründete, zeitkontinuierliche Modellierung des Wassertransports in kleinen ländlichen Einzugsgebieten, Mitteilungen des Instituts für Hydrologie und Wasserwirtschaft, Heft 61, Universität Karlsruhe, Germany, 1997.

Mualem, Y.: A new model for predicting the hydraulic conductivity of unsaturated porous media, Water Resour. Res., 12, 513-522, 1976.

Refsgaard, J. C. and Storm, B.: MIKE SHE, in: Computer Models of Watershed Hydrology, edited by: Singh, V. P., 809-846, Water Resources Publications, Highland Ranch, Colorado, USA, 1995.

Reggiani, P., Sivapalan, M., and Hassanizadeh, S. M.: A unifying framework for watershed thermodynamics: balance equations for mass, momentum, energy and entropy and the second law of thermodynamics, Adv. Water Resour., 22(4), 367-398, 1998.

Reggiani, P., Hassanizadeh, S. M., Sivapalan, M., and Gray, W. G.: A unifying framework for watershed thermodynamics: constitutive relationships, Adv. Water Resour., 23(1), 15-39, 1999.

Reggiani, P., Sivapalan, M., and Hassanizadeh, S. M.: Conservation equations governing hillslope responses: exploring the physical basis of water balance, Water Resour. Res., 36(7), 1845-1863, 2000.

Reggiani, P. and Rientjes, T. H. M.: Flux parameterization in the representative elementary watershed approach: Application to a natural basin, Water Resour. Res., 41(4), W04013, doi:10.1029/2004WR003693, 2005.

Schäfer, D.: Bodenhydraulischen Funktionen eines Kleineinzugsgebiets - Vergleich und Bewertung unterschiedlicher Verfahren. Dissertation, Institute of Hydromechanics, University of Karlsruhe, Germany, 1999.

Shipitalo, M. J. and Butt, K. R.: Occupancy and geometrical properties of Lumbricus Terrestris L. burrows affecting infiltration, Pedobiologia, 43, 782-794, 1999.

Simunek, J., Vogel, T. N., and van Genuchten, M. T.: The SWMS2D code for simulating water and solute transport in two dimensional variably saturated media - Version 1.2. Research Report 132, US Salinity Lab., Agric. Res. Serv. USDA, Riverside, California, USA, 1994.

Sivapalan, M., Takeuchi, K., Franks, S. W., Gupta, V. K., Karambiri, H., Lakshmi, V., Liang, X., McDonnell, J. J., Mendiondo, E. M., O’Connel, P. E., Oki, T., Pomeroy, J. W., Schertzer, D., Uhlenbrook, S., and Zehe, E.: IAHS decade on Predictions of Ungauged Basins (PUB): Shaping an exciting future for the hydrological sciences, Hydrol. Sci. J., 48(6), 857-879, 2003.

Sivapalan, M.: Linking hydrologic parameterizations across a range of spatial scales: hillslope to catchment to region, IAHS Publication Number 212, Proceedings of Yokohama Symposium, 115123, 1993.

Turner, M. G.: Landscape ecology: the effect of pattern on process. Annual Review of Ecology and Systematics, 20, 171-197, 1989. Turner, M. G. and Gardner, R. H.: Landscape Ecology in Theory 
and Practice - Pattern and Process, Springer-Verlag, New York, USA, 2001.

van Genuchten, M. T.: A closed-form equation for predicting the hydraulic conductivity of unsaturated soils, Soil Sci. Soc. Am. J., 44, 892-898, 1980.

Vogel, H.-J., Tölke, J., Schulz, V. P., Krafczyk, M., and Roth, K.: Comparison of a lattice-boltzmann model, a full-morphology model, and a pore network model for determining capillary pressure-saturation relationships, Vadoze Zone Journal, 4, 380388, 2005.

Vogel, H. J. and Roth, K.: Moving through scales of flow and transport in soil, J. Hydrol., 272, 95-106, 2003.

Viney, N. R. and Sivapalan, M.: Scaling of hydrologic conceptualizations: Approaches to handling subgrid variability, Hydrol. Process., 18(8), 1395-1408, doi:10.1002/hyp.1419, 2004.

Watt, A. S.: Pattern and process in the plant community, J. Ecol., 35(1), 1-22, 1947.

Zhang, G. P. and Savenije, H. H. G.: Rainfall-runoff modeling in a catchment with a complex groundwater flow system: application of the Representative Elementary Watershed (REW) approach, Hydrol. Earth Syst. Sci., 9, 243-261, 2005, http://www.hydrol-earth-syst-sci.net/9/243/2005/.
Zehe, E.: Stofftransport in der ungesättigten Bodenzone auf verschiedenen Skalen, Dissertation, University of Karlsruhe, Germany, 1999.

Zehe, E. and Flühler, H.: Slope scale variation of flow patterns in soil profiles, J. Hydrol., 247(1-2), 116-132, 2001.

Zehe, E., Maurer, Th., Ihringer, J., and Plate, E.: Modelling water flow and mass transport in a loess catchment, Phys. Chem. Earth, Part B, 26(7-8), 487-507, 2001.

Zehe, E. and Blöschl, G.: Predictability of hydrologic response at the plot and catchment scales - the role of initial conditions, Water Resour. Res., 40, W10202, doi:10.1029/2003WR002869, 2004.

Zehe, E., Becker, R., Bardossy, A., and Plate, E.: Uncertainty of simulated catchment sale runoff response in the presence of threshold processes: role of initial soil moisture and precipitation, J. Hydrol., 315(1-4), 183-202, 2005a.

Zehe, E., Lee, H., and Sivapalan, M.: in: Predictions in Ungauged Basins: INTERNATIONAL PERSPECTIVES ON STATE-OFTHE-ART AND PATHWAYS FORWARD, Proceedings of the Australia-Japan Workshop on PUB Working Groups, edited by: Franks, S. W., Sivapalan, M., Takeuchi, K., and Tachikawa, Y., IAHS Publication 301, Paper 14, 2005 b. 